\title{
Qual o papel da pedagogia crítica nos estudos de língua e de cultura?
}

Entrevista com Henry A. Giroux

Manuela Guilherme

\section{OpenEdition}

\section{Journals}

Edição electrónica

URL: http://journals.openedition.org/rccs/962

DOI: $10.4000 /$ rccs.962

ISSN: 2182-7435

\section{Editora}

Centro de Estudos Sociais da Universidade de Coimbra

\section{Edição impressa}

Data de publição: 1 Dezembro 2005

Paginação: 131-143

ISSN: 0254-1106

\section{Refêrencia eletrónica}

Manuela Guilherme, "Qual o papel da pedagogia crítica nos estudos de língua e de cultura? », Revista Crítica de Ciências Sociais [Online], 73 | 2005, colocado online no dia 01 outubro 2012, criado a 19 abril 2019. URL : http://journals.openedition.org/rccs/962 ; DOI : 10.4000/rccs.962 


\title{
Qual o papel da pedagogia crítica nos estudos de língua e de cultura? Entrevista com Henry A. Giroux'
}

\author{
MANUELA GUILHERME
}

Henry Giroux posicionou-se como figura destacada na teoria da educação radical no final dos anos oitenta. Não só retomou as propostas para uma educação cívica dos principais teóricos da educação do século XX, nomeadamente Dewey, Freire e outros como os reconstrucionistas Counts, Rugg e Brameld, mas também expandiu as teorias desses autores avançando com a ideia de uma "pedagogia de fronteira". A sua proposta pode ser entendida como a aplicação de uma perspectiva cosmopolita pós-colonial à noção norte-americana de educação cívica democrática. Giroux elabora uma visão para a educação que corresponde aos desafios que se apresentam, no início deste século XXI, às sociedades ocidentais e que decorrem das profundas mudanças demográficas e políticas pelas quais elas estão a passar na actualidade. Quanto mais tempo levar aos políticos da educação para assumir com seriedade as suas recomendações, mais tempo e possibilidades estaremos a perder e a negligenciar. De facto, os educadores, em todos os níveis do sistema educativo e por todo o mundo, sentem uma desmotivação crescente, e mesmo frustração, porque se vêem ultimamente forçados a recuar em vez de avançar, no sentido de criarem desafios para si próprios, quer na sua condição de profissionais, quer de cidadãos, a fim de corresponderem às necessidades das nossas sociedades em rápida mudança. Giroux tem incitado os educadores e os académicos a reagir a estas forças paralisantes e a serem críticos, criativos e esperançosos em relação ao potencial que, tanto eles como os seus estudantes, podem oferecer, a fim de contrariar as tendências políticas conservadoras que têm imposto uma definição de excelência em educação que significa mais uma submissão às pressões de mercado do que excelência educativa nos termos de uma produção intelectual inovadora. Giroux incita, ao mesmo tempo, à análise crítica e ao reconhecimento de possibilidades na educação e advoga tanto a independência como a responsabilidade para professores e estudantes, isto é, clama por dignidade e respeito para com as instituições de educação, professores e estudantes. Giroux reafirmou corajosamente a natureza política do trabalho diário dos investigadores em educação e dos próprios educadores. Para além disto, Giroux teorizou eloquentemente uma pedagogia dos Estudos Culturais baseada no que fora

\footnotetext{
${ }^{1}$ Esta entrevista foi publicada originalmente em inglês, na revista Language and Intercultural Communication, 6(2). Agradecemos aos responsáveis por esta revista a autorização concedida para a publicação da versão portuguesa.
} 
proposto pelo próprio teórico da educação, Raymond Williams. De facto, a área dos Estudos Culturais tem sido problematizada, e é em si própria problemática, embora muito rica e prometedora, dado que tem fracturado fronteiras entre disciplinas. No entanto, precisamente por esta razão, exige uma teorização completa que descreva os seus objectivos bem como os fundamentos do seu conteúdo epistemológico e dos seus procedimentos. Giroux deu, neste campo, importantes contributos para descrever estes processos ao rastrear as relações entre língua, texto e sociedade, as novas tecnologias e as estruturas de poder que lhes subjazem. Esta foi a sua resposta quer aos críticos dos Estudos Culturais, quer aos académicos que neles se têm refugiado para seguir uma moda ou para encontrar uma saída das suas disciplinas tradicionais agora em descrédito. Indicou ainda novos caminhos, que não se limitam a recuperar a nova área, politicamente empenhada e cientificamente fundamentada, dos Estudos Culturais, iniciada por Raymond Williams e Stuart Hall, mas oferecem uma a análise das implicações das novas tecnologias no intercâmbio e na recriação de conhecimento novo por entre as novas teias de poder. Justifica-se, portanto, mencionar o sucesso de Giroux na identificação de novos modos de representação e de aprendizagem.

Giroux iniciou, de facto, uma nova escola de pensamento e, com a sua voz afirmativa, vibrante e empenhada, instigou à acção tanto os teóricos como os práticos da educação. Ao advogar uma pedagogia da responsabilidade, assumiu a responsabilidade pelo seu próprio papel social e político de académico. Concentrou a sua atenção na redefinição e no reforço da noção de "público" em relação ao conhecimento, à educação e à vida cívica, sobretudo incorporando conceitos tais como "tempo e espaço públicos". Enquanto muitos teóricos da educação se concentraram na influência da sociedade no contexto educativo, Giroux, embora pondo criticamente a nu as forças políticas e económicas que ameaçam a independência e a criatividade na escola e na academia, é mais ousado e chama, de forma clara, a nossa atenção para o potencial transformador da escola e da academia no contexto mais amplo da sociedade, recuperando, assim, a natureza política da actividade pedagógica. Por fim, embora focalize o seu discurso nos aspectos gerais da educação, na educação para a cidadania e nos estudos culturais, Giroux oferece, através das suas propostas para a teoria e a prática educativas, aos teóricos e práticos da língua e da comunicação intercultural os fundamentos para a renovação das suas visões e das suas práticas. 
Todo o seu trabalbo demonstra uma preocupação profunda e consistente com a vida cívica num mundo globalizado. Como é que define uma forma mais globalizada do exercício da cidadania?

A cidadania evoca uma noção do social na qual os indivíduos têm deveres e responsabilidades uns para com os outros. Uma noção globalizada de cidadania expande o conceito de contrato social para além das fronteiras do estado-nação, evocando uma noção mais ampla de democracia na qual o global se torna o espaço onde se exercita a coragem cívica, a responsabilidade social, a política e a compaixão pelo destino dos outros. É evidente que, por exemplo, a obrigação dos cidadãos para com o meio ambiente não pode ser vista meramente como um problema nacional. Ao mesmo tempo, uma noção globalizada de cidadania acentua as questões de responsabilidade e de interdependência, definindo a cidadania não apenas como a emanação política de direitos, mas também como um repto de natureza ética tendo em vista diminuir a distância entre a promessa e a realidade de uma democracia global. É também importante reconhecer que a ideia de cidadania não pode ser separada dos espaços nos quais a cidadania se fomenta e se desenvolve. Isto sugere que qualquer luta por uma noção significativa e globalizada de cidadania, que encoraje o debate e a responsabilidade social, deve fomentar e desenvolver as esferas públicas, tais como escolas, os meios de comunicação social e outras instituições nas quais se possam desenvolver pedagogias críticas cívicas. A noção de cidadania global sugere que a política deve confrontar-se com o poder que actualmente se afastou do controlo local e do controlo do Estado. Devem desenvolver-se novas estruturas políticas, instituições globais e movimentos sociais que possam alcançar e controlar os movimentos de um poder não controlado, em particular do poder económico. Uma cidadania efectiva, no sentido global, significa capacitar as pessoas para terem uma palavra na elaboração das leis internacionais que governam o comércio, o meio ambiente, o trabalho, a justiça criminal, a protecção social, etc. A cidadania, enquanto essência da política, deve ajustar-se às novas formações sociais, que as actuais instituições sociais e políticas do Estado-nação não estão em condições de influenciar, limitar ou controlar.

\section{Quais são as capacidades específicas que este novo cidadão cosmopolita deve desenvolver?}

Os cidadãos de uma democracia global devem estar conscientes da natureza interactiva de todos os aspectos da vida cultural, espiritual e física. Isto significa ter um entendimento profundo da natureza relacional das dependências globais, quer falemos da ecosfera ou dos circuitos do capital. Em segundo lugar, os cidadãos devem ter uma cultura multifacetada, de um modo que não só lhes dê acesso às novas tecnologias da informação e dos media, mas também lhes permita ser transgressores de fronteiras preparados para se empenharem, aprenderem, interpretarem e serem tolerantes e responsáveis relativamente a tudo o que envolve diferença e alteridade. Isto sugere que se reclamem os valores da importância mútua, da dignidade e da responsabilidade ética como centrais a qualquer noção viável de cidadania. Está aqui em causa o reconhecimento de que existe uma certa virtude cívica e valor ético no aumento da nossa exposição à diferença e à alteridade. Os cidadãos devem cultivar lealdades que se estendam para além do Estado-nação, para além da distinção teó- 
rica entre amigo e inimigo mediada exclusivamente pelas fronteiras nacionais. A cidadania, como uma forma de aquisição de poder, implica claramente a aquisição de capacidades que nos permitam examinar criticamente a história e ressuscitar as memórias perigosas através das quais o conhecimento expande as possibilidades de autoconhecimento e de actuação crítica e social. Nem só o conhecimento indígena nos confere poder. Os indivíduos devem também estabelecer alguma distância relativamente ao conhecimento do seu berço, das suas origens e da especificidade do seu lugar. Isto implica apropriar-se daqueles conhecimentos que emergem da dispersão, das viagens, das transgressões de fronteiras, da diáspora e através das comunicações globais. Uma noção cosmopolita da sociedade deve reconhecer a importância da divergência e de uma cultura de questionamento para qualquer conceito de democracia. A esfera pública global deve ser um espaço onde a autoridade possa ser questionada, o poder responsabilizado e a divergência vista como positiva. Há um autoritarismo crescente em muitas partes do globo, especialmente nos Estados Unidos. Para nos confrontarmos com esta ameaça à democracia por todo o mundo, é essencial que os educadores, pais, jovens, trabalhadores e outros impeçam que a democracia degenere em formas de nacionalismo patrioteiro. Isto significa que os educadores, e os outros, terão de revigorar a democracia assumindo que um projecto pedagógico que dê prioridade ao debate, à deliberação, à divergência, ao diálogo e ao espaço público deve ser central a qualquer noção viável de cidadania global. De igual modo, se a cidadania for global, deve desenvolver-se um sentido de humanismo radical que compreenda a justiça social e ambiental fora das fronteiras nacionais. O sofrimento humano não se extingue nas fronteiras do Estado-nação.

Na minha perspectiva, uma das suas propostas mais inspiradoras é a exigência de um papel mais dignificante e empenbado do educador em todos os niveis do sistema educativo. Confirma que este é um dos principais objectivos da sua escrita?

Sempre argumentei que os professores devem ser tratados como um recurso público crítico, essencial não só para uma experiência educativa afirmativa dos estudantes mas também para a formação de uma sociedade democrática. No plano institucional, isto significa dar aos professores a oportunidade de exercer o poder sobre as suas próprias condições de trabalho. Não podemos separar a actividade docente das condições económicas e políticas que enquadram a sua condição profissional, isto é, o seu trabalho académico. Isto significa que deveriam ter tanto o tempo como o poder de instituir as condições estruturais que lhes permitam produzir o currículo, colaborar com os encarregados de educação, realizar investigação e trabalhar com as comunidades. Para além disto, a dimensão dos edifícios escolares deve ser limitada de modo a permitir aos professores e outros construir, manter e animar o sentimento de uma sociedade democrática para eles e para os seus estudantes. Falamos não só da questão do número de alunos por turma, mas também do modo como o espaço pode ser organizado institucionalmente como uma parte de um projecto político compatível com a formação de sociedades vivas e democráticas. Em segundo lugar, deveria dar-se aos professores a liberdade de desenhar os currículos escolares, de empreender investigação partilhada com outros professores e com outros fora da escola e ainda de ter um papel central na governação da escola 
e do seu próprio trabalho. A autoridade pedagógica dos professores não pode separar-se das questões de poder e de governação. Os educadores devem ser considerados como intelectuais públicos que estabelecem a ligação entre as ideias críticas, as tradições, as disciplinas e os valores da esfera pública no seu dia-a-dia. Mas, ao mesmo tempo, os educadores devem assu- mir a responsabilidade de ligar o seu trabalho às questões sociais mais amplas, interrogando-se sobre o que significa capacitar os seus alunos para escrever textos políticos, para ser perseverantes perante a derrota, para analisar os problemas sociais e para aprender a utilizar os instrumentos da democracia e a marcar a diferença como agente social.

Também propõe uma interação evidente entre teoria e prática, que os nossos sistemas académicos e as nossas sociedades têm procurado separar. Poderia explicar as vantagens de as articular para efeitos de uma educaşão para a cidadania democrática?

A educação para a cidadania deve levar a sério a ligação entre teoria e prática, reflexão e acção. Acontece, muitas vezes, a teoria na academia deslizar para uma forma de teorismo na qual se torna um fim em si própria, e é relegada para os cumes de uma existência secreta, ou se torna muito afectada e supremamente etérea, oferecendo o caminho mais rápido para a proeminência académica. Mas a teoria não é necessariamente um luxo relacionado com a fantasia do poder intelectual. Pelo contrário, a teoria é um recurso que nos permite definir e responder a problemas à medida que vão emergindo em contextos específicos. O seu poder transformador reside na possibilidade de gerar formas de acção e não na sua capacidade de resolver problemas. A sua natureza política decorre da sua capacidade de fazer imaginar um mundo diferente e de fazer agir de modo diferente e este é o seu principal contributo para qualquer noção viável de educação para a cidadania. O que está aqui em causa não é se a teoria é relevante, uma questão de resposta tão óbvia como a pergunta sobre se o pensamento crítico é importante, mas quais devem ser as responsabilidades públicas e políticas da teoria, em particular na teorização de uma política global para o século XXI. A teoria não é apenas contemplação ou o caminho para o estrelato académico, pelo contrário, trata sobretudo da intervenção no mundo, do desenvolvimento de ideias para o espaço mundano da vida pública, do aprofundamento da responsabilidade social e da participação colectiva no mundo. Se a aprendizagem é uma parte fundamental da transformação social, a teoria é um instrumento essencial para o estudo de toda a gama de práticas diárias que circulam através das diversas formações sociais e para a descoberta de melhores formas de conhecimento e modos de intervenção para contrapor aos desafios de um autoritarismo crescente ou de um pessimismo fabricado.

Tem sido frequentemente acusado de apresentar a educação como um meio de instilar propaganda ideológica nos estudantes e tem rejeitado estas acusações propondo uma pedagogia crítica. De que modo, na sua opinião, se promove um espírito livre através da pedagogia crítica?

Parece-me que, longe de instilar propaganda nos estudantes, uma pedagogia crítica parte da noção de que o conheci- mento e o poder devem estar sempre sujeitos a debate, ser responsabilizados e estar empenhados criticamente. Está no âmago 
da própria definição de pedagogia crítica a vontade colectiva de reformar as escolas e de desenvolver modos de prática pedagógica em que professores e alunos se tornem agentes críticos que questionem activamente e negociem a relação entre teoria e prática, entre a análise crítica e o senso comum e entre a aprendizagem e a transformação social. Isto não é propriamente uma receita propagandística. Penso que a pedagogia crítica é muitas vezes considerada perigosa porque se constrói sobre um projecto que atinge a essência do que é a educação e porque se enquadra numa série de perguntas importantes mas normalmente ignoradas, tais como: "Porque é que nós [educadores] fazemos o que fazemos do modo como o fazemos"? "Que interesses serve a escolaridade"? "Como devemos perceber e relacionarmo-nos com os diversos contextos nos quais a educação acontece"? No entanto, a pedagogia crítica não se interessa apenas em oferecer aos estudantes novas formas de pensar criticamente e de agir com autoridade na sala de aula, também trata de preparar professores e alunos com as necessárias competências e conhecimentos que lhes permitam questionar crenças e mitos de raízes profundas que legitimam as mais arcaicas e discriminatórias práticas sociais que, por sua vez, estruturam todos os aspectos da sociedade, e ainda de os responsabilizar para a sua intervenção no mundo. Em outras palavras, a pedagogia crítica forja a crítica e a acção tanto através da linguagem do cepticismo como da possibilidade.

A importância dos departamentos de bumanidades tem sido posta em causa nas universidades de todo o mundo pela gestão universitária, pelo mercado de trabalho e pela sociedade em geral. Na sua opinião, como podem estes departamentos encarar o desafio não só da sobrevivência como também de contrariar a "crise da cultura", que cita a partir de Raymond Williams, e ainda de reclamar a relevância da sua função?

Nos últimos anos, tenho estado a trabalhar numa série de projectos que tratam de vários aspectos interrelacionados: o papel essencial da cultura, em particular da cultura de massas entendida como o espaço principal onde a pedagogia e a aprendizagem acontecem, especialmente no que diz respeito aos jovens; o papel que os académicos e os trabalhadores da cultura podem assumir como intelectuais do espaço público conscientes da força constituinte que a cultura tem na formação da memória pública, da consciência moral e da actividade política; o significado da universidade, em especial das humanidades, enquanto esfera pública essencial para a manutenção de uma democracia viva e dinâmica, apesar do assalto das forças da empresarialização, e da centralidade da juventude como um registo ético para ava- liar a natureza da mudança do contrato social desde os anos oitenta e das suas implicações para um discurso mais amplo sobre a esperança e o futuro. As humanidades têm sido tradicionalmente tanto um refúgio como um instrumento para reflectir sobre estes assuntos, embora em condições históricas com poucas semelhanças com o presente. Isto torna-se particularmente evidente à medida que as condições de produção de conhecimento, da identidade nacional e da cidadania se têm transformado, numa ordem mundial pós-11 de Setembro marcada por uma rápida globalização e pela expansão das novas tecnologias electrónicas, pela consolidação dos media globais, pela desindustrialização, a desregulação e o emagrecimento empresarial globais, pela privatização de bens e serviços públicos e pela introdução da 
lógica de mercado em todos os aspectos da vida social.

A "crise" das humanidades reflecte a crise na sociedade mais ampla acerca do significado e da viabilidade das instituições que se definem a si próprias mais como um bem público do que privado. A vocacionalização em curso do ensino superior, a transformação do currículo em mercadoria, o papel crescente da universidade na segurança nacional e a transformação dos estudantes em consumidores têm enfraquecido a capacidade das humanidades de oferecer aos estudantes o conhecimento e as competências de que necessitam para aprender como se governa e como se desenvolvem as capacidades necessárias para a deliberação, a argumentação lógica e a acção social. A incursão da cultura empresarial e militar na vida universitária põe em causa a responsabilidade da universidade de conferir aos estudantes uma educação que lhes permita reconhecer o sonho e a promessa de uma democracia substantiva. Embora tenhamos de reconhecer que as humanidades têm de concorrer com os desenvolvimentos nas ciências, os novos media, a tecnologia e outros campos do desenvolvimento científico e do conhecimento, a sua primeira responsabilidade é tratar estes assuntos, não apenas de forma pragmática tendo em conta as ideias e as competências a adquirir, mas também como espaços de intervenção política e ética profundamente ligados à missão de preparar estudantes que consigam imaginar um futuro democrático para todas as pessoas.

Por outro lado, esta época de crise, medo e insegurança tem revigorado o debate sobre o papel que as humanidades e a universidade podem cumprir na criação de uma cultura pública plural essencial para animar os preceitos básicos de uma vida pública democrática. As questões da história, das relações globais, das preocupações éticas, a criatividade e do desenvolvi- mento de novas literacias e modos de comunicação deveriam ser centrais à educação nas humanidades e à discussão que lhes é inerente, mas, ao mesmo tempo, estas discussões têm, na maior parte das vezes, descuidado assuntos fundamentais, tais como a linguagem da educação cívica enquanto elemento do discurso mais amplo da actividade política e da cidadania crítica numa sociedade globalizada. Mais particularmente, um melhor entendimento das razões pelas quais as humanidades têm evitado o desafio dos discursos críticos capazes de interrogar os modos como a sociedade se representa si própria (por exemplo, a discrepância implícita na representação do apogeu da democracia no preciso momento do seu esvaziamento) e de saber como e porquê os indivíduos não conseguem assumir criticamente essas representações, é fundamental para perceber se os educadores devem intervir nas relações sociais opressoras que tão frequentemente eles próprios legitimam.

Tendo em conta estes contextos, os educadores das humanidades devem fazer novos tipos de perguntas começando por: como é que os educadores reagem às questões de valor no que diz respeito à "utilidade" das humanidades e ao conjunto dos objectivos pelos quais se devem orientar? Quais os conhecimentos de maior valor? O que significa reivindicar autoridade num mundo onde as fronteiras estão a alterar-se constantemente? Qual o papel das humanidades num mundo em que a "produção imaterial" de conhecimento se tem tornado no tipo mais importante de capital? Como pode a pedagogia ser entendida como uma prática moral e política e não uma estratégia técnica ao serviço da cultura empresarial? E que relação deveriam as humanidades ter com os jovens de modo a que estes desenvolvam capacidade de acção, particularmente no que diz respeito às suas obrigações de cidadania crítica e de vida pública 
numa paisagem global e cultural radicalmente diferente? À medida que a cidadania se vai privatizando e os jovens são cada vez mais formados para se tornarem sujeitos consumidores e não sujeitos sociais críticos, torna-se mais imperioso que os educadores que trabalham nas humanidades repensem o espaço do social e desenvolvam uma lin- guagem crítica na qual as noções de bem público, as questões públicas e a vida pública se tornem centrais e prevaleçam sobre a linguagem de mercado despolitizante e privatizante. No centro desta questão, a meu ver, está o papel que o ensino superior deveria cumprir na sua função de esfera pública democrática.

\section{Tem questionado a percepção tradicional do "intelectual". Como é que esta noção se aplica} ao mundo contemporâneo?

Sempre acreditei que a noção do "intelectual" reside numa variedade importante de registos sociais, culturais e políticos. Ao contrário da ideia de que os intelectuais são um grupo especializado de peritos, eu tenho argumentado que cada um de nós é um intelectual na medida em que temos a capacidade de pensar, de gerar ideias, de ser autocríticos e de articular conhecimentos (de onde quer que surjam) com formas de autodesenvolvimento e de desenvolvimento social. Ao mesmo tempo, aqueles intelectuais que podem ter o luxo de definir a sua função social através da produção de ideias intelectuais têm uma responsabilidade acrescida de examinar o modo como o poder permeia as instituições, os indivíduos, as formações sociais e o dia-a-dia de modo a permitir ou a anular os valores, identidades e relações democráticas. Para ser mais concreto, acredito que a obrigação mais importante que os intelectuais têm para com o conhecimento é precisamente a de reconhecer a sua articulação com o poder não como uma relação de complementaridade, mas de oposição. Em minha opinião, os intelectuais, quer dentro, quer fora da academia, devem estabelecer a ligação das ideias com o mundo e integrar as suas capacidades e conhecimentos numa luta mais ampla pela justiça, ideias e valores democráticos. Os intelectuais têm a responsabilidade não só de fazer prevalecer a verdade no mundo e lutar contra a injustiça onde quer que ela esteja, mas também de organizar as paixões colectivas no sentido de impedir o sofrimento humano, o genocídio e as formas diversas de não-liberdade ligadas à dominação e à exploração. Os intelectuais têm ainda a responsabilidade de analisar os modos como a língua, a informação e o sentido se articulam para organizar, legitimar e fazer circular valores, para estruturar a realidade e para oferecer noções específicas de acção e de identidade. Este último desafio requer dos intelectuais públicos um novo tipo de cultura e de entendimento crítico em relação à emergência dos novos media e tecnologias electrónicas e ao novo e poderoso papel que eles têm como instrumentos de uma pedagogia pública.

A reflexão crítica é uma dimensão essencial da justiça e é fundamental para a educação cívica, e é precisamente através da manutenção da justiça e da democracia vivas no domínio público que os intelectuais exprimem a sua responsabilidade para com o mundo global. Actualmente, a noção de intelectual, tal como Pierre Bourdieu nos recorda, tornou-se sinónimo de relações públicas, apologista adulador e falante de palavra fácil nos media. Os educadores, na sua qualidade de intelectuais públicos, necessitam de um novo vocabulário que estabeleça a ligação entre esperança, cidadania social e educação nos termos de uma democracia substantiva. $\mathrm{O}$ que estou a 
sugerir é que os educadores precisam de um vocabulário novo que exprima não só a nossa leitura crítica, mas também o nosso empenho em movimentos de transformação social. Eu também acredito que não basta evocar a relação entre teoria e prática, crítica e actividade social. Qualquer tentativa de dar vida nova a uma política democrática substantiva deve considerar tanto o modo como as pessoas aprendem a ser activas politicamente quanto o tipo de trabalho pedagógico que é necessário empreender em diversos tipos de espaços públicos de modo a permitir às pessoas usarem todos os seus recursos intelectuais tanto para realizar uma crítica profunda das instituições existentes como para lutar pelo cumprimento da promessa de uma democracia radical global. Enquanto intelectuais no espaço público, os educadores e outros trabalhadores culturais devem entender as razões pelas quais os instrumentos que usámos no passado estão desadequados no presente, não correspondendo, portanto, aos problemas que os Estados Unidos, e outras partes do globo, enfrentam actualmente. Para ser mais concreto, enfrentamos o desafio da incapacidade dos discursos críticos actuais de fazerem a ponte entre o modo como a sociedade se representa a si própria e o modo como e porquê os indivíduos se não reconhecem nessas representações nem as assumem criticamente a fim de intervir nas relações sociais opressivas que elas frequentemente legitimam. Se combinar os papéis mutuamente interdependentes do cidadão crítico e activo, o trabalho intelectual pode, no seu melhor, levar ao exercício da coragem cívica como prática política, uma prática que se inicia quando a vida de cada um deixa de ser considerada um dado adquirido. Esta atitude não só faz com que o trabalho intelectual exija a responsabilização do poder dominante, mas também torna concreta a possibilidade de transformar a esperança e a política num espaço ético e num acto público que confronta o fluxo da experiência diária e o peso do sofrimento social com a força do indivíduo e da resistência colectiva e o projecto inacabado da transformação social democrática. O caminho para o autoritarismo começa quando as sociedades deixam de se interrogar e, quando esse interrogar cessa, isso acontece porque os intelectuais ou se tornaram cúmplices com esse silêncio ou o produziram activamente. É evidente que os intelectuais críticos têm a responsabilidade de se opor a este silêncio surdo perante um barbarismo global emergente, como é demonstrado pelo número crescente de fundamentalismos económicos, políticos e religiosos.

Uma das suas afirmações mais radicais é que todo o acto educativo é político e que cada acto político deveria ser pedagógico. Do mesmo modo que o seu trabalbo cruza diferentes áreas disciplinares, também tenta ligar diversas instituições nas quais a pedagogia se desenrola: a educação, a política e os media, para referir apenas alguns. Quais são as suas razões para estas incursões e os riscos que daí advêm?

Nas últimas décadas, tentei reavivar as visões penetrantes de teóricos como António Gramsci, Raymond Williams, Edward Said e outros que defenderam que a força pedagógica da cultura, no sentido mais amplo, se tem tornado num dos espaços políticos mais importantes na luta por ideias, valores e capacidade de acção. A educação permanente é um elemento fundamental do processo de criação daquelas identidades e valores que integram a narrativa do que constitui a política. No passado, a educação limitava-se à instrução, mas tem-se tornado óbvio que 
a maior parte da educação que acontece actualmente, e que é tão vital para a democracia, tem lugar num espaço mais amplo que inclui a cultura do ecrã, a cultura de massas, a Internet e todos os velhos e novos media. Tenho chamado a atenção para estes novos espaços de educação, a que eu chamo o reino da pedagogia pública, que considero essenciais a qual- quer noção de política porque são espaços nos quais as pessoas, as mais das vezes, aprendem, desaprendem ou onde simplesmente não encontram o conhecimento que os prepare para serem sujeitos activos e críticos, capazes de não apenas interpretar a sociedade e o mundo em que vivem mas também de vestir o manto da governação.

Tem dedicado grande parte do seu trabalho mais recente ao que considera um tratamento injusto da juventude nas sociedades contemporâneas, quer pelas instituições públicas, quer pelas privadas (por exemplo, o governo, o sistema educativo, a imprensa e a sociedade em general). Que papel podem os educadores, em particular, desenvolver para contrariar esta tendência?

Bem, a primeira coisa que devem fazer é reconhecer as obrigações dos adultos para com os jovens se, de facto, vamos levar a sério não só o contrato social mas também a própria possibilidade de um futuro democrático. A segunda coisa que deve ser feita, é tentar perceber estas forças, especialmente o neoliberalismo, o neoconservadorismo, o militarismo e o fundamentalismo religioso, que vêem os jovens como coisas ou como algo terrivelmente descartável, especialmente os jovens pobres e os jovens de cor, e tentar perceber ainda como estas forças podem ser contrariadas em cada instituição por meio de políticas que encaram a juventude verdadeiramente como um investimento social e não como uma ameaça, um recurso para o exército ou uma coisa.

Como vê a introdução de uma nova área académica interdisciplinar que pretende desenvolver competências interculturais, isto é, aumentar a capacidade dos alunos para comunicarem e interagirem eficazmente por entre as culturas, tanto no âmbito nacional como internacional? Como podem os educadores implementar esta área interdisciplinar e intercultural no âmbito de uma pedagogia crítica? Será que este projecto corresponde à sua sugestão de criação de uma "nova linguagem que exprima uma solidariedade global"?

Penso que esta questão das competências interculturais deve ser compreendida no âmbito de uma noção mais ampla de literacia ligada tanto à aquisição de capacidade de acção como ao reconhecimento de que as questões da diferença estão inevitavelmente ligadas a questões de respeito, tolerância, diálogo, bem como à nossa responsabilidade para com os outros. A literacia multicultural, enquanto intervenção discursiva, é um passo essencial, não só para uma noção mais ampla de auto-representação, mas também para uma noção mais global de intervenção democrática. A literacia, neste sentido, é, não só plural e abrangente, mas também o espaço no qual se tornam possíveis novas práticas dialógicas e relações sociais. A literacia, tal como a uso aqui, constrói uma espécie de ponte necessária à democracia e, ao mesmo tempo, oferece formas de tradução que desafiam as estratégias de senso comum e de dominação. Ao mesmo tempo, as competências interculturais devem ser relacionadas com as dinâmicas centrais do poder de modo a assumir as diferenças e exclusões e o seu processo de 
formação como parte de uma narrativa histórica constituída por luta e negociação. Desta forma, estas competências geram mais do que interpretação e tomada de consciência; actuam também como modos de inter- pretação crítica nos quais o diálogo e a interpretação estão intrinsecamente ligados a modos de intervenção, nos quais as diferenças culturais são vistas como um recurso e não como uma ameaça à democracia.

O estilo da sua escrita é muito forte e idiossincrático e tem sido objecto tanto de crítica como de elogio. Alguns dos seus leitores consideram-no demasiado obscuro e impregnado de ideologia, enquanto outros o consideram vibrante, estimulante e muito inspirador. Eu pertenço a estes últimos e gostaria de lhe perguntar até que ponto o desenho da sua escrita épropositado e que propósitos serve.

Na última década, tenho tentado tornar a minha escrita mais acessível a um público mais amplo ainda que sem comprometer o seu rigor teórico. Isto parece causar muitos problemas àqueles académicos cujo discurso é bastante impenetrável, altamente especializado e ligado a definições estreitas de carreirismo. Os académicos, em especial os da esquerda nos Estados Unidos, são, na sua maior parte, muito maus escritores, um problema que resulta menos de falta de capacidade de escrita do que de uma noção misteriosa de profissionalismo. Muitos deles vivem no "mundo da teoria" e, em geral, dirigem-se a públicos muito especializados. Por um lado, muito do seu trabalho é tributário de um tipo de ironia ou de engenho pós-modernos ou é tão pedante que é destituído de qualquer paixão ou integridade políticas. Por outro lado, o nível estabelecido nos Estados Unidos, em matéria de clareza e de estilo, é tão baixo que se torna sempre difícil atingir um público mais amplo se afrontamos os níveis convencionais de estilo e de linguagem, tal como faço no meu trabalho. Claro que as queixas acerca do meu trabalho não se resumem a questões de estilo, mas respeitam também ao facto de eu conferir nele um lugar central ao elemento político e isto de um modo que torna o projecto que lhe está subjacente muito óbvio. A reacção contra a escrita empenhada, se não contra a actividade política empenhada, é tão forte nas nossas universidades, nos media e em outros espaços estatuídos da pedagogia pública, que afirmar a importância da actividade política, como sendo um aspecto fundamental da nossa vida diária e da nossa aprendizagem representa um combate incrivelmente difícil, mas que é absolutamente necessário travar.

Tem sido muito crítico em relação às condições que o mundo contemporâneo oferece aos jovens, nomeadamente mais vigilância nas escolas, a chamada excelência na educação traduzida em avaliação mais normalizada, uma cultura comercializada, etc. Não tenho dúvidas de que está muito consciente de que é muito difícil para os educadores críticos, enquanto indivíduos profissionais sobrecarregados com as exigências do governo, da gestão escolar, dos estudantes e encarregados de educação, contrariar estas por si sós. A sua obra tem, sem duivida, inspirado e apoiado os esforços desses educadores. Gostaria de lhes dirigir alguma mensagem especial?

Sim, estes são tempos muito difíceis, mas o que está em jogo é muito importante e, se damos valor à democracia e temos qual- quer esperança que seja no futuro, devemos continuar a lutar para entrelaçar educação e democracia, aprendizagem e 
transformação social, excelência e equidade. A única alternativa é a descrença ou a cumplicidade e nenhum educador merece isso. Também penso que é importante reconhecer que estas lutas se travam em todo o mundo e que, portanto, não estamos sozinhos, nem o deveríamos estar, a travar estas lutas cruciais que vão determinar o destino da democracia global no século XXI.

Que justificação encontra para o crescente interesse dos professores de língualcultura estrangeiras pela sua obra, apesar da tradicional falta de interesse desses professores pelas teorias críticas da escolaridade e da pedagogia?

Claro que temos de reconhecer que, historicamente, houve bastantes professores de línguas/culturas estrangeiras que estabeleceram a ligação entre língua e pedagogia crítica, particularmente os participantes da TESOL. Penso que muito desse trabalho foi produzido antes de tempo e só agora existem as condições que permitem aos educadores reconhecer a importância dele no actual contexto global educativo/pedagógico/discursivo. À medida que se vai tornando claro que não se pode separar as questões do uso da língua das questões do diálogo, da comunicação, da cultura e do poder, os assuntos da política e da pedagogia tornam-se cruciais para quem entende a pedagogia como uma questão política e as políticas da língua como sendo questões de profunda reflexão pedagógica. Durante vários anos, argumentei que a língua, sendo tanto objecto como sujeito de mestria, interpretação e empenho, é o espaço no qual as pessoas negociam os elementos mais fundamentais das suas identidades, as relações entre eles e os outros e a sua relação com o resto do mundo. Também fui claro ao afirmar que é difícil, se tivermos isto em conta, tratar a língua como se fosse apenas uma questão de técnica. Torna-se evidente que a sua importância reside no reconhecimento de que se trata de uma prática moral e política profundamente relacionada tanto com os assuntos de actuação crítica como com o combate infindável para expandir e aprofundar a própria democracia.
As questões de língua e cultura são essenciais para o modo como a natureza de cada um se constrói e a forma como cada um actua na sua qualidade de intelectual. A língua é, portanto, o fundamento cultural e material em função do qual os educadores tentam definir o significado e o objectivo da pedagogia na formação e aquisição de formas particulares de actuação individual e social. Esta é uma questão a que me tenho referido desde há trinta anos, mas também uma questão que tenho tomado como parte de uma preocupação mais ampla com o que significa tornar a pedagogia mais política no âmbito da sua tarefa de expandir os valores, relações, identidades e esferas públicas democráticos. É aqui que me parece que o meu trabalho reflecte a actual conjuntura histórica. Aprender uma língua estrangeira é um empreendimento essencialmente humanístico, e não uma tarefa afecta às elites ou estritamente metodológica, e a força da sua importância deve decorrer da relevância da sua função afirmativa, emancipadora e democrática.

O meu trabalho trata a língua como um modo de aprendizagem e de dissensão que é igualmente fundamental para configurar e traduzir as fronteiras entre o público e o privado e para lidar com as questões da política, do poder, da consciência pública e da coragem cívica. Mais do que nunca, a língua precisa de ser revitalizada como parte de uma pedagogia pública que exalta a imaginação, expande a autonomia do individuo e aprofunda uma noção possível 
da actividade política. A língua é parte do que Edward Said chamou uma política da mundialidade, intrinsecamente ligada às questões da história, do poder e a uma cultura da interrogação e da luta democrática. A pedagogia crítica, no meu trabalho, tem sempre levado a sério estas últimas e pode ser que este trabalho esteja agora a ser redescoberto e usado pelos professores de língua/cultura estrangeiras. Penso que muitos estão desejosos de um discurso que ligue a crítica à esperança, o conhecimento à paixão e a pedagogia à justiça. Gostaria de acreditar que o meu trabalho pode oferecer-lhes alguma esperança neste tempo de escuridão.

Henry Giroux mudou-se para o Canadá em 2004 e detém actualmente a cátedra da Rede Global de Televisão dos Estudos de Comunicação na Universidade de MacMaster. Embora os pais fossem originários do Canadá, Giroux nasceu e viveu sempre nos Estados Unidos. Começou a sua carreira na educação como professor de história no ensino secundário e prosseguiu um percurso académico brilhante pelo qual é reconhecido internacionalmente. Giroux é membro de vários conselhos editoriais de revistas nacionais e internacionais importantes nas áreas da Educação e dos Estudos Culturais e muitas das suas obras foram premiadas pela Associação Americana de Estudos da Educação por serem consideradas as obras mais significativas nos anos da sua publicação. A extensa lista das suas publicações inclui vários livros, capítulos de livros, artigos em revistas destacadas focando diferentes aspectos ligados à Educação e aos Estudos Culturais (ver www.henryagiroux.com). De salientar em especial, em 1988, Teachers as Intellectuals, New York: Bergin and Garvey; em 1992, Border Crossings: Cultural Workers and the Politics of Education, New York: Routledge; em 1997, Channel Surfing: Race Talk and the Destruction of Today's Youth, London: MacMillan; em 2001, com K. Myrsiades, Public Spaces, Private Lives: Democracy beyond 9/11, Lanham: Rowman \& Littlefield; em 2003, Beyond the Corporate University: Culture and Pedagogy in the New Millenium, Lanham: Rowman \& Littlefield; em 2004, com S. Searls-Giroux, Take Back Higher Education: Race, Youth and the Crisis of Democracy in the Post Civil Rigts Era, New York: Palgrave MacMillan. 